\title{
Investigation of Oligosaccharides for Prebitoic Action on Vaginal Lactobacilli
}

\author{
Jayashri Gajananrao Mahore, Bhavana Bhikhubai Rohit, Sanjeevani Shekhar Deshkar \\ Department of Pharmaceutics, Dr. D. Y. Patil Institute of Pharmaceutical Sciences and Research, Pimpri, Pune, Maharashtra, INDIA.
}

\begin{abstract}
Objective: Vaginitis is a very common gynaecological problem in women of all age groups resulted in millions of visit to physician. Decrease in vaginal Lactobacilli is one of the reasons of Bacterial vaginitis. Approach that could improve decreased level of Lactobacilli and inhibit growth of pathogenic bacteria can be alternative to antibiotic therapy. Oligosaccharides influence the growth of Lactobacilli species and benefits vaginal ecosystem. The present study was designed to evaluate prebitoic potential of oligosaccharides in vaginitis. Methodology: The potential of oligosaccharides to stimulate the growth of three selected vaginal Lactobacilli strains was studied by optical density, $\mathrm{pH}$, titrable acidity and dry mass after $48 \mathrm{~h}$ of incubation. The antimicrobial effect of vaginal Lactobacilli in presence of oligosaccharide against pathogenic bacteria E. coli and C. albicans was studied by agar diffusion method. Vaginal irritation test was studied on female Swiss albino mice. Results and Discussion: Increased lactic acid production and lowering of $\mathrm{pH}$ by Lactobacilli strains in presence of oligosaccharides confirmed that oligosaccharide can stimulate the growth of selected Lactobacilli species. Optical density and dry biomass was also increased during $48 \mathrm{~h}$ of incubation. Higher zone of inhibition was observed in presence
\end{abstract}

of prebiotic compared to control (without prebiotic). Vaginal irritation study showed no significant changes. Conclusively, oligosaccharides supported the growth of selected strains and could restore bacterial environment.

Key words: Lactobacilli, Fructo-Oligosaccharide (FOS), Galacto-Oligosaccharide (GOS), Prebiotic, Vaginitis.

Key message: The FOS and GOS stimulated the growth of Lactobacilli strain and Suppressed growth of harmful species in the vagina ecosystem.

\section{Correspondence :}

Jayashri G. Mahore, Assistant Professor, Department of Pharmaceutics, Dr. D. Y. Patil, Institute of Pharmaceutical Sciences and Research, Pimpri, Pune-18, Maharashtra, INDIA.

Phone: 09922943257

Email: jayashri_mahore@rediffmail.com

DOI: 10.5530/jyp.2017.9.98

\section{INTRODUCTION}

Human microbiota is microorganisms colonized in human body. Microbiota generally resides on skin, mouth, gut and vagina. ${ }^{1}$ Female genital tract is one of the major sites occupied by microbiota, commonly dominated by Doderlen's bacilli (Lactobacillus species). ${ }^{2}$ Presence of Lactobacilli is important sign of healthy vagina which inhibits the growth of pathogenic microorganism. Lactobacilli avoid growth, hold and expansion of pathogenic microorganism. Antimicrobial activity of Lactobacilli is owed to $\mathrm{H}_{2} \mathrm{O}_{2}$, bacteriocins and biosurfactants production. ${ }^{3}$ Vaginal Lactobacilli produces lactic acid from anaerobic glycolysis of glycogen that comes from shedding of vaginal epithelium. Lactic acid produced by Lactobacilli in concentration of $110 \mathrm{mM}$ with acidic vaginal milieu $\mathrm{pH} 3.5$ is the reason to prevent attack of pathogenic microorganism in vagina. Another probable reason is competition for the supplements, steric avoidance for the adhesion to the epithelium. It is quite difficult to identify different species of Lactobacilli colonizing vagina with culture dependent methods such as $\mathrm{H}_{2} \mathrm{O}_{2}$ production test, catalase reaction and sugar utilization test. ${ }^{4}$ Whereas culture independent identification methods like sequencing of $16 \mathrm{~S}$ rRNA of bacterial colonies, terminal restriction fragment length polymorphism (T-RFLP) of $16 \mathrm{~S}$ rRNA, qPCR and next generation sequencing (NGS) have wide applications in the field of microbiology. ${ }^{5}$ Common Lactobacilli isolated from the vagina include L. acidophilus, L. fermentum, L. plantarum, L. brevis, L. jensenii, L. casei, L. cellobiosus, L. leichmanii, L. delbrueckii, and L. salivarius. Of all these species, L. acidophilus, L. fermentum and L. casei has been the vaginal Lactobacillus most widely accepted to be predominant. ${ }^{6}$ Composition of vaginal flora may change due to disturbances in hormone levels, anti-toxin medications, sexual exercises and improper cleanliness. ${ }^{7}$ Compromise in healthy vaginal flora i.e. decrease in Lactobacilli is the main reason for bacterial vaginitis (BV). If asymptomatic BV is untreated, it can extend to Sexually transmitted infections (STI), including Neisseria gonorrhea, Chlamydia trachomatis, Trichomonas vaginalis, Herpes simplex infection sort 2 (HSV-2), Human papilloma infection (HPV), and in addition HIV, premature birth, post-abortal contamination, unsuccessful labour, and upper conceptive tract infection. Symptomatic BV is treated with oral metronidazole for 7 days, metronidazole gel for 5 days or clindamycin cream for 7 days. Resistance offered by microorganism to antimicrobials is currently becoming a major concern. ${ }^{8}$

Antibiotic therapy causes disturbance of normal flora i.e. decrease in Lactobacilli and it is not possible to restore the pre-BV flora after antibiotic treatment. Use of suppositories to treat vaginal infection is also restricted because of constant irritation and noncompliance of working women. Recurrence is common after antibiotic therapy, may be because of résistance of pathogenic microorganism and/or failure to restore vaginal flora to pre BV condition. Recurrence of BV is 30\% inside 3 months and $50 \%$ within 6 months of antimicrobial treatment. ${ }^{9}$

Because of recurrence of bacterial vaginosis after antimicrobial therapy, concept of probiotic to restore the vaginal flora came into existence. ${ }^{10}$ Probiotics can be characterized as "live microorganisms which when regulated in sufficient sums give a medical advantage on the host. ${ }^{11}$ Pharmacological action of probiotic formulation depends on colony forming unit of respective microorganism. It is very difficult to maintain stability of probiotic formulation as oxygen, temperature, humidity and pressure may affect probiotic formulation unfavourably. To overcome disadvantages of probiotics, it was necessary to explore new option that can be detrimental on pathogenic bacteria and beneficial to useful bacteria. ${ }^{12}$ 
Prebiotic are non-digestible oligosaccharides that are not digested in upper gastrointestinal tract and fermented in colon. Fermentation of oligosaccharides provides energy to beneficial microbial flora of lower intestine. FOS and GOS are qualified as prebiotics. ${ }^{13}$

From the literature review it was observed that prebiotic could help to restore pre-vaginitis environment. Rosseau et al. ${ }^{14}$ studied the effect of FOS and GOS on selected endogenous vaginal Lactobacilli strains showing probiotic properties. The aim of the present study was to investigate effect of FOS and GOS on three dominant strains, Lactobacilli acidophilus, Lactobacillus fermentum, Lactobacillus casei, that are considered as predominant Indian women vaginal Lactobacilli. ${ }^{15}$

\section{MATERIAL AND METHODS}

\section{MATERIALS}

Lactobacilli acidophilus (ATCC 4796), Lactobacillus fermentum (ATCC 14931), Lactobacillus casei (ATCC 393) were generously provided by Dr. D. Y. Patil Arts, Commerce and Science College, Pimpri, Pune. Fructooligosaccharides (FOS) and Galacto-oligosaccharides (GOS) were purchased from Himedia, Mumbai, India. All other chemicals used were of analytical grade.

\section{METHOD}

\section{Effect of Oligosaccharides on the Growth of Selected Lactobacilli Strains: Inoculum Preparation and Cultivation Conditions ${ }^{14}$}

Reconstituted MRS broth supplemented with FOS and GOS medium was used in the study. Reconstituted standard broths $(250 \mathrm{~mL})$, containng, tryptone $10 \mathrm{~g} / \mathrm{L}$, meat extract $10 \mathrm{~g} / \mathrm{L}$, yeast extract $5 \mathrm{~g} / \mathrm{L}$, tween $801.1 \mathrm{~g} / \mathrm{L}$, potassium phosphate dibasic $2 \mathrm{~g} / \mathrm{L}$, sodium acetate $5 \mathrm{~g} / \mathrm{L}$, ammonium citrate $2 \mathrm{~g} / \mathrm{L}$, magnesium sulphate $0.2 \mathrm{~g} / \mathrm{L}$ and manganese sulphate $0.05 \mathrm{~g} / \mathrm{L}$ and oligosaccharides (FOS and GOS) were added to the broth at a final concentration of $10 \mathrm{~g} / \mathrm{L}$. The experimental media were sterilized at $121^{\circ} \mathrm{C}$ for 15 min before inoculation. The overnight (18 hours) cultures were used for inoculation of media at $2 \%(\mathrm{v} / \mathrm{v})$ concentration. Reconstituted media was incubated for 48 hours under anaerobic conditions. Samples were taken at every 4 hours of growth to determine i) \% Titratable acidity ii) $\mathrm{pH}$ iii) Optical density at 600nm iv) Determination of dry mass / biomass v) Antimicrobial activity against E. coli and C. albicans.

\section{Determination of Lactic Acid Production ${ }^{16}$}

Titratable acidity (as \% lactic acid) of the sample was determined in triplicate using $0.1 \mathrm{M} \mathrm{NaOH}$ using phenolphthalein as an indicator. The titratable acidity was expressed as a percentage of that of lactic acid.

The $\%$ titratable acidity was calculated by using formula:

$$
\% \operatorname{acid}=\frac{\mathrm{N} \times \mathrm{V} \times \mathrm{M}}{\mathrm{S} \times 10}
$$

Where, $\quad \mathrm{N}=$ Normality of standard $\mathrm{NaOH}$ used for titration.

$\mathrm{V}=$ volume of standard $\mathrm{NaOH}$ used for titration in $\mathrm{mL}$

$\mathrm{M}=$ Molecular weight of predominant acid in the sample divided by the number of hydrogen ions in the acid molecules that are titrated.

$\mathrm{S}=$ Sample size in $\mathrm{mL}$ or $\mathrm{gm}$.

\section{$\mathrm{pH}$}

The $\mathrm{pH}$ of each sample was measured by an electronic digital type $\mathrm{pH}$ meter $^{17}$ (Equip-Tronic, Mumbai, India). The $\mathrm{pH}$ meter was standardized using reference $\mathrm{pH} 4.0$ and $\mathrm{pH} 7.0$ buffer solutions.

\section{Optical Density at $600 \mathrm{~nm}^{18}$}

The optical density was measured by using UV-Visible spectrophotometer (Shimadzu Analytical Pvt. Ltd, Japan) at $600 \mathrm{~nm}$.

\section{Determination of Dry Mass/Biomass ${ }^{19}$}

For drymass or biomasss, the reconstituted MRS broth sample was centrifuged at 4,000 rpm (Cooling Centrifuge, Remi Electro lab, Mumbai) for $20 \mathrm{~min}$. Clear supernant was removed carefully and pellets were collected. Weight of pellets was taken immediately and pellets were dried at $80^{\circ} \mathrm{C}$ for 24 hours and again weight of dry pellets was taken.

\section{Determination of Antimicrobial Activity against E. coli and C. albicans ${ }^{16}$}

Cell-free supernatant was collected by centrifugation at 4,000 rpm for $15 \mathrm{~min}$. Antimicrobial assay was performed by agar well diffusion method. MacConkey agar and potato dextrose agar were used for E. coli and C. albicans respectively. After solidification of agar $0.1 \mathrm{~mL}$ of overnight cultures of E. coli and C. albicans was spread and $100 \mu \mathrm{L}$ of cell free supernant was added in $6 \mathrm{~mm}$ wells. Plates were kept in refrigerator to facilitate diffusion for $4 \mathrm{~h}$. Then plates were incubated aerobically at $37^{\circ} \mathrm{C}$ for 24 hours in case of E. coli and for $48^{\circ} \mathrm{C}$ in case of C. albicans. Zone of inhibitions were recorded in triplicate

\section{Vaginal Irritation Study Using Mice ${ }^{20}$}

In order to study the safety of prebiotic effect (FOS and GOS), vaginal irritation study using female Swiss albino mice was conducted. Fifteen mice were divided into 3 groups. The FOS and GOS gel was prepared using nutrient agar $(2 \% \mathrm{w} / \mathrm{v})$ as a gelling agent. The prepared gel was applied by micropipette to the vagina of mice in quantity of $0.1 \mathrm{gm}$ once daily for 10 days. The toxic manifestation, if any, on the vaginal region was assessed by observing the vaginal mucosa at preselected time intervals between and after treatment for 10 days. The findings were recorded for each animal.

\section{RESULT AND DISCUSSION}

\section{Effect of Oligosaccharides on the Growth of Selected Lactobacilli Strains: \\ Effect of FOS and GOS on Lactic acid production \\ (\% titratable acidity) by Lactobacilli strains.}

The amount of lactic acid produced by the selected strains of Lactobacilli is represented in Table 1. Study showed that the percentage of lactic acid produced by Lactobacillus acidophilus was higher than Lactobacillus casei. Lactobacillus acidophilus uses EmbdenMeyerhoff-Parnas (EMB) pathway using $\mathrm{NADH}$ as the cofactor and the enzyme lactate dehydrogenase and produces lactic acid and pyruvic acid as main metabolites. Whereas Lactobacillus casei utilizes EMB pathways as well as 6-phosphogluconate/ phosphoketolase pathways and produces $\mathrm{CO}_{2}$ and ethanol along with lactic acid. ${ }^{21}$

\section{Changes in $\mathrm{pH}$ by Lactobacilli strains containing Fructoligosaccharide (FOS) and Galactooligosaccharide (GOS):}

Figure 1 indicate distinct $\mathrm{pH}$ lowering effect of FOS and GOS compared to control (without prebiotics). It proved the stimulating effect of FOS and GOS on Lactobacilli. Reduction in $\mathrm{pH}$ showed strong relationship to production of lactic acid which is main metabolic product produced by the Lactobacilli. 
Mahore et al.: Oligosaccharides: new approach to treat bacterial vaginitis

Table 1: Effect of FOS And GOS on Lactic Acid Production (\% Titratable Acidity) by Lactobacillus acidophillus, Lactobacilus fermentum and Lactobacillus casei.

\begin{tabular}{|c|c|c|c|c|c|c|c|c|c|}
\hline \multirow[b]{3}{*}{ Time(hrs) } & \multicolumn{9}{|c|}{ \%Titratable acidity (Lactic acid \%) } \\
\hline & \multicolumn{3}{|c|}{ Lactobacillus acidophillus } & \multicolumn{3}{|c|}{ Lactobacillus fermentum } & \multicolumn{3}{|c|}{ Lactobacillus casei } \\
\hline & $\begin{array}{c}\text { Control } \\
\text { (without } \\
\text { prebiotic) }\end{array}$ & $\begin{array}{c}\text { FOS } \\
(1 \% w / v)\end{array}$ & $\begin{array}{c}\text { GOS } \\
(1 \% w / v)\end{array}$ & $\begin{array}{c}\text { Control } \\
\text { (without } \\
\text { prebiotic) }\end{array}$ & $\begin{array}{c}\text { FOS } \\
(1 \% w / v)\end{array}$ & $\begin{array}{c}\text { GOS } \\
(1 \% w / v)\end{array}$ & $\begin{array}{l}\text { Control } \\
\text { (without } \\
\text { prebiotic) }\end{array}$ & $\begin{array}{c}\text { FOS } \\
(1 \% w / v)\end{array}$ & $\begin{array}{c}\text { GOS } \\
(1 \% w / v)\end{array}$ \\
\hline 0 & $0.12 \pm 0.03$ & $0.15 \pm 0.03$ & $0.15 \pm 0.03$ & $0.10 \pm 0.06$ & $0.13 \pm 0.06$ & $0.11 \pm 0.03$ & $0.02 \pm 0.05$ & $0.05 \pm 0.05$ & $0.05 \pm 0.05$ \\
\hline 4 & $0.15 \pm 0.03$ & $0.23 \pm 0.02$ & $0.26 \pm 0.01$ & $0.12 \pm 0.03$ & $0.20 \pm 0.09$ & $0.15 \pm 0.03$ & $0.05 \pm 0.05$ & $0.15 \pm 0.03$ & $0.15 \pm 0.03$ \\
\hline 8 & $0.22 \pm 0.01$ & $0.28 \pm 0.01$ & $0.35 \pm 0.04$ & $0.15 \pm 0.03$ & $0.3 \pm 0.07$ & $0.26 \pm 0.01$ & $0.13 \pm 0.03$ & $0.2 \pm 0.02$ & $0.2 \pm 0.02$ \\
\hline 12 & $0.35 \pm 0.04$ & $0.32 \pm 0.04$ & $0.38 \pm 0.02$ & $0.21 \pm 0.01$ & $0.31 \pm 0.06$ & $0.28 \pm 0.01$ & $0.2 \pm 0.02$ & $0.26 \pm 0.01$ & $0.28 \pm 0.01$ \\
\hline 16 & $0.34 \pm 0.02$ & $0.39 \pm 0.04$ & $0.405 \pm 0.06$ & $0.28 \pm 0.01$ & $0.40 \pm 0.06$ & $0.40 \pm 0.06$ & $0.22 \pm 0.01$ & $0.29 \pm 0.02$ & $0.33 \pm 0.03$ \\
\hline 20 & $0.40 \pm 0.06$ & $0.55 \pm 0.03$ & $0.51 \pm 0.03$ & $0.40 \pm 0.06$ & $0.50 \pm 0.02$ & $0.56 \pm 0.02$ & $0.33 \pm 0.03$ & $0.42 \pm 0.01$ & $0.44 \pm 0.01$ \\
\hline 24 & $0.51 \pm 0.03$ & $0.67 \pm 0.07$ & $0.71 \pm 0.06$ & $0.56 \pm 0.02$ & $0.67 \pm 0.06$ & $0.62 \pm 0.03$ & $0.44 \pm 0.01$ & $0.52 \pm 0.07$ & $0.48 \pm 0.01$ \\
\hline 32 & $0.74 \pm 0.03$ & $0.91 \pm 0.05$ & $0.87 \pm 0.03$ & $0.74 \pm 0.04$ & $0.71 \pm 0.08$ & $0.83 \pm 0.02$ & $0.58 \pm 0.06$ & $0.72 \pm 0.02$ & $0.67 \pm 0.06$ \\
\hline 36 & $0.83 \pm 0.02$ & $1.07 \pm 0.04$ & $0.92 \pm 0.02$ & $0.87 \pm 0.03$ & $0.91 \pm 0.02$ & $0.92 \pm 0.02$ & $0.71 \pm 0.05$ & $0.81 \pm 0.02$ & $0.76 \pm 0.06$ \\
\hline 40 & $0.92 \pm 0.02$ & $1.29 \pm 0.05$ & $1.14 \pm 0.03$ & $0.90 \pm 0.02$ & $1.13 \pm 0.02$ & $1.10 \pm 0.03$ & $0.83 \pm 0.02$ & $1.05 \pm 0.02$ & $0.94 \pm 0.06$ \\
\hline 44 & $0.90 \pm 0.02$ & $1.20 \pm 0.04$ & $1.11 \pm 0.02$ & $0.81 \pm 0.02$ & $1.02 \pm 0.05$ & $1.07 \pm 0.02$ & $0.79 \pm 0.05$ & $0.95 \pm 0.03$ & $0.97 \pm 0.04$ \\
\hline 48 & $0.85 \pm 0.03$ & $0.92 \pm 0.03$ & $0.92 \pm 0.02$ & $0.78 \pm 0.02$ & $0.98 \pm 0.03$ & $0.96 \pm 0.02$ & $0.80 \pm 0.06$ & $1.03 \pm 0.06$ & $0.78 \pm 0.07$ \\
\hline
\end{tabular}

Lactic acid and Short Chain fatty acids produced by Lactobacilli contribute to the maintenance of a low vaginal $\mathrm{pH}$ which is thought to be an important control mechanism preventing colonisation by pathogens. Acidification of vagina produces unfavourable condition for growth of Salmonella typhimurium, Helicobacter priori, Candida albicans, E. coli and G. vaginalis.22 The reduction in $\mathrm{pH}$ was from 6-6.5 $(\mathrm{t}=0)$ to $4-4.5$ after 48 hours of incubation. The normal $\mathrm{pH}$ of vaginal fluid is about $4.5-5.5$. The resulting low $\mathrm{pH}$ is important for preventing non indigenous organisms in the vagina.

\section{Effect of FOS and GOS on growth curve of Lactobacilli strain}

Figure 2 showed that optical density of selected Lactobacilli strains was higher in reconstituted broth containing prebiotic than control (without prebiotic) which confirms the ability of oligosaccharide to stimulate the growth of selected Lactobacilli.

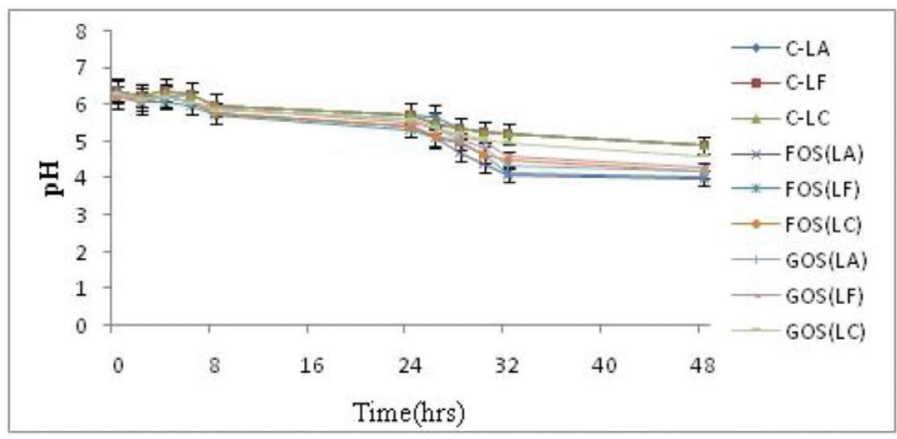

*Error bars represent standard deviations of replicates.

Figure 1: Changes in pH by Lactobacillius acidophillus, Lactobacillus fermentum, Lactobacillus casei in Presence of FOS, GOS and Control (without prebiotic)
The optical densities of all the Lactobacilli strains containing FOS tended to be slightly higher than the optical densities of the GOS and the control. Shorter chain fructo-oligosaccharides containing primarily fructose chains and fructose chain with terminal glucose bound by $\beta$ $(1,2)$ bond glycocidic linkages could have undergone rapid degradation in highly acidic environment. Rapid degradation of FOS was supporting faster growth of Lactobacilli that was indicated by higher optical density in FOS as compared to GOS..$^{23}$ The bacterial growth started to lag phase from early period of Inoculation. Lactobacillus acidophilus, Lactobacillus fermentum and Lactobacillus casei growth approached to exponential phase after 8 hours. Then, all bacterial growth reached to stationary phase after 28 hours and turned to be relatively constant for 48 hours.

\section{Determination of dry mass on Lactobacilli strain containing fructoligosaccharide (FOS) and galactooligosaccharide (GOS)}

The dry mass of the Lactobacillus acidophilus, Lactobacillus fermentum and Lactobacillus casei, containing FOS, GOS and control are represented in Figure 3. Upon observing the cellular concentration in terms of dry mass of Lactobacilli strains, cultivated in reconstituted MRS medium supplemented with prebiotic as a function of time, a potential increase in dry mass was observed at the end of 48 hours in sample containing prebiotic to that of control. Higher increase in dry mass in FOS could be attributed to transport systems for sucrose in Lactobacilli including the oligosaccharide transporter MsmEFGK and the sucrose phosphotransferase system Pts1BCA. Both the transport systems are responsible for internalization of FOS. ${ }^{24}$ Because of these transport systems Lactobacilli could utilize FOS rapidly than GOS as a carbon source giving higher biomass in FOS than GOS.

\section{Antimicrobial activity of Lactobacillus acidophilus containing FOS and GOS against E.Coli and C.albicans}

The sensitivity of the pathogenic microorganisms to inhibitory substances produced by selected Lactobacilli is presented in Table 2 and Figure 4. The inhibitory activity was distinct towards Gram -ve E. coli compared 


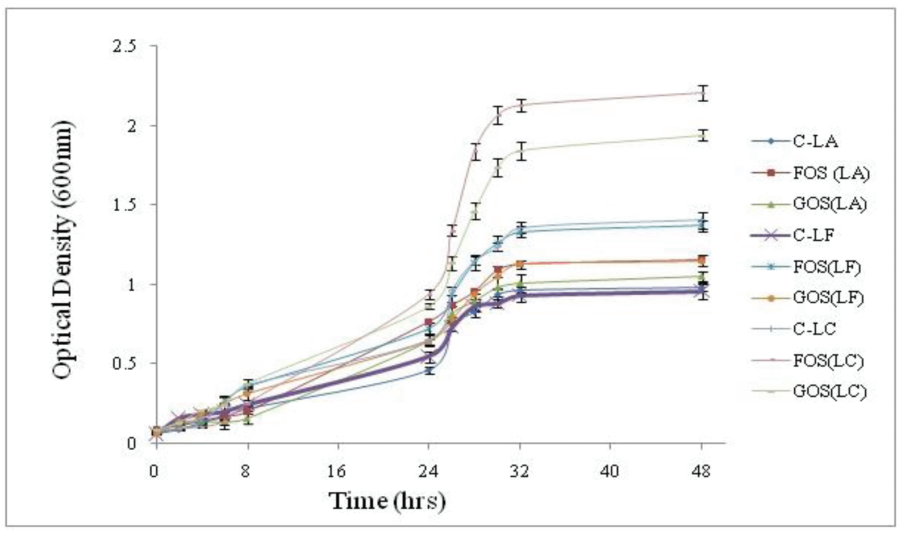

*Error bars represent standard deviations of replicates.

Figure 2: Growth of Lactobacillus acidophillus, Lactobacillus fermentum, Lactobacillus casei in reconstituted MRS broth either with (1\% W/V FOS and $1 \% \mathrm{~W} / \mathrm{V}$ GOS) or without prebiotic.

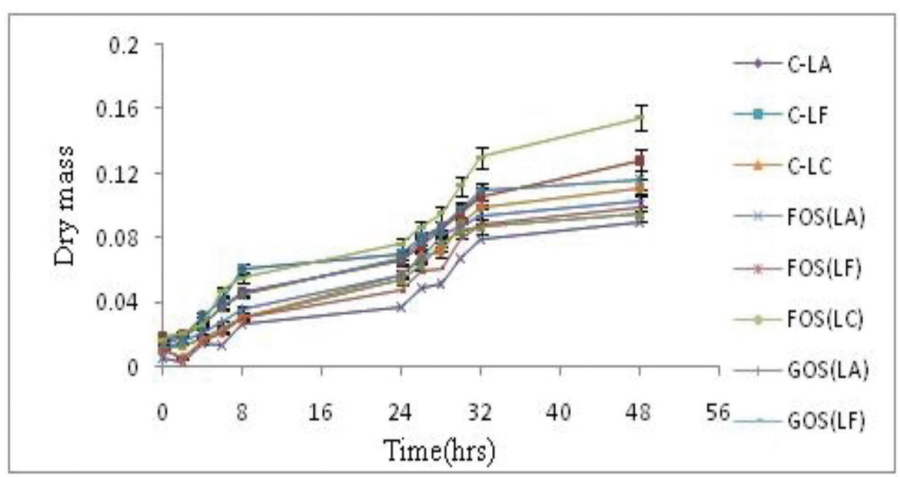

*Error bars represent standard deviations of replicates

Figure 3: Changes in Dry Mass of Lactobacillius acidophillus, Lactobacillus fermentum, Lactobacillus casei containing FOS, GOS and Control (Without Prebiotic).

Table 2: Antimicrobial Activity of Lactobacillus acidophillus, Lactobacilus fermentum and Lactobacillus casei Containing FOS and GOS against E. coli

\begin{tabular}{|c|c|c|c|c|c|c|c|c|c|c|}
\hline \multirow[b]{3}{*}{ Strain } & \multirow[b]{3}{*}{$\begin{array}{l}\text { Incubation } \\
\text { time(hrs) }\end{array}$} & \multicolumn{9}{|c|}{ Inhibition zone $(\mathrm{mm})$} \\
\hline & & \multicolumn{3}{|c|}{ Lactobacillus acidophillus } & \multicolumn{3}{|c|}{ Lactobacilus fermentum } & \multicolumn{3}{|c|}{ Lactobacillus casei } \\
\hline & & $\begin{array}{l}\text { (without } \\
\text { prebiotic) }\end{array}$ & $\begin{array}{l}\text { Reconstituted } \\
\text { MRS broth } \\
\text { with FOS }\end{array}$ & $\begin{array}{l}\text { Reconstituted } \\
\text { MRS broth } \\
\text { withGOS }\end{array}$ & $\begin{array}{l}\text { (without } \\
\text { prebiotic) }\end{array}$ & $\begin{array}{l}\text { Reconstituted } \\
\text { MRS broth } \\
\text { with FOS }\end{array}$ & $\begin{array}{l}\text { Reconstituted } \\
\text { MRS broth } \\
\text { withGOS }\end{array}$ & $\begin{array}{l}\text { (without } \\
\text { prebiotic) }\end{array}$ & $\begin{array}{c}\text { Reconstituted } \\
\text { MRS broth } \\
\text { with FOS }\end{array}$ & $\begin{array}{l}\text { Reconstituted } \\
\text { MRS broth } \\
\text { withGOS }\end{array}$ \\
\hline \multirow{4}{*}{ E. coli } & Control & - & - & - & - & - & - & - & - & - \\
\hline & $\mathrm{T}_{6}$ & $2.25 \pm 0.21$ & $5.3 \pm 0.28$ & $4.2 \pm 0.21$ & $2.55 \pm 0.35$ & $6.3 \pm 0.28$ & $5.6 \pm 0.28$ & $3.8 \pm 0.14$ & $12.7 \pm 0.21$ & $10.7 \pm 0.21$ \\
\hline & $\mathrm{T}_{24}$ & $4.3 \pm 0.28$ & $12.3 \pm 0.28$ & $10.6 \pm 0.21$ & $5.6 \pm 0.28$ & $13.6 \pm 0.14$ & $11.3 \pm 0.21$ & $8.55 \pm 0.35$ & $15.3 \pm 0.28$ & $13.4 \pm 0.35$ \\
\hline & T48 & $5.65 \pm 0.28$ & $15.3 \pm 0.35$ & $14.4 \pm 0.42$ & $8.2 \pm 0.42$ & $18.4 \pm 0.42$ & $16.6 \pm 0.28$ & $10.5 \pm 0.42$ & $20.3 \pm 0.35$ & $18.6 \pm 0.42$ \\
\hline
\end{tabular}

to C. albicans, both being common vaginal infection causative agents. No zone of inhibition was observed against C. albicans. The absence of effect on $C$. albicans growth can be correlated with the resistance of yeasts to acidic conditions and $\mathrm{H}_{2} \mathrm{O}_{2} \cdot{ }^{25}$

Significant zone of inhibitions were observed against E. coli. Bacteriocin (antimicrobial peptides or proteins) are produced by almost all genera of lactic acid bacteria. ${ }^{26}$ The FOS and GOS stimulate the growth of Lactobacilli strain and suppress growth of potentially harmful species in the vagina ecosystem.

\section{Vaginal Irritation Study Using Mice}

The Microscopic examination of vaginal tissues were evaluated by scoring system as given by normal(0), mild (1), moderate (2), severe (3). FOS group (Group II) revealed mild focal hyperplasia of squamous epithelium and multifocal mild lymphocytic infiltration at lamina propria (1). GOS group (Group III) revealed mild diffuse lymphocytic infiltration at lamina propria (1). Thus vaginal irritation study showed no significance changes in vagina after application of FOS and GOS (Figure 5).

\section{CONCLUSION}

The selected Lactobacilli strains were able to grow on FOS and GOS as indicated by the increase in turbidity i.e. optical density, lactic acid production and dry mass obtained after $48 \mathrm{~h}$ of incubation as compared to control(without prebiotic). Prebiotic had a greater influence on the growth of Lactobacilli strain and a greater $\mathrm{pH}$ lowering effect in a reconstituted MRS medium containing FOS and GOS. There were significant

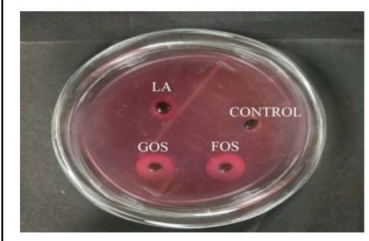

(A)

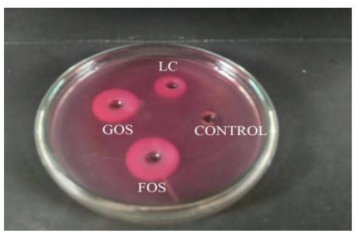

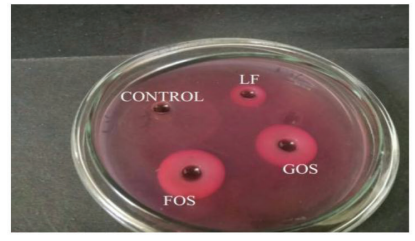

(B)

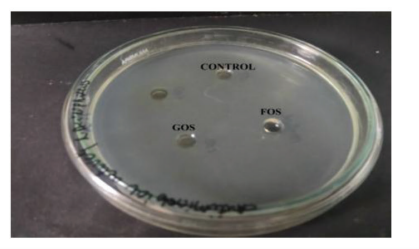

Figure 4: Antimicrobial activity against E. coli in presence of prebiotic (FOS and GOS), Lactobaciilus Strains (without prebiotic), control (without Prebiotic and Lactobacilli strains) of; (A) Lactobacillius acidophillus, (B)Lactobacillius fermentum, (C) Lactobacillius casei, (D) Antimicrobial Activity of Lactobacillius acidophillus against C. albicans in presence of prebiotic FOS and GOS.

increase in the inhibition activity of Lactobacilli strains in presence of FOS and GOS as compared to control. Therefore from the results of all the parameters, it was concluded that prebiotics promoted the growth of Lactobacilli that generated lactic acid to lower the vaginal $\mathrm{pH}$ and secreted antibacterial substances that inhibited the adhesion and replication of 


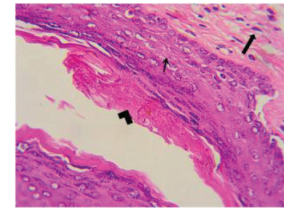

(A)

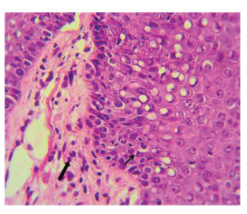

(B)

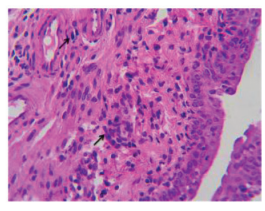

(C)
Figure 5: Microscopic examination of vaginal tissues of mice (A) control group (B) FOS group (C) GOS group.

the pathogenic bacteria. FOS and GOS showed potential prebiotic property for selected Lactobacilli strains.

\section{CONFLICTING INTEREST}

The authors are declared no conflict of interest.

\section{ABBREVIATION USED}

HIV: Human immunodeficiency virus; LA: Lactobacillus acidophilus; LF: Lactobacillus fermentum; LC: Lactobacillus case; E.Coli: Escherichia coli; $\mathrm{H}_{2} \mathrm{O}_{2}$ : Hydrogen peroxide; FOS: Fructooligosaccharides; GOS: Galactooligosaccharides.

\section{REFERENCES}

1. Lloyd-Price J, Galeb A, Curtis H. The healthy human microbiome. Geno. Medicine. 2016; 8(51):2-11.

2. Redondo-Lopez $V$, Cook R, Sobel J. Emerging role of Lactobacilli in the control and maintenance of the vaginal bacterial micro flora. Rev. Infect. Dis. 1990; 12(5):56-72.

3. Wadher KJ, Mhaore JG and Umekar MJ. Probiotics: Living mediciens in health maintenance and disease prevention. Int. J. Pharm. Biol. Sci. 2010;1(3):1-9

4. Aldunate M, Srbinovski D, Hearps C. Antimicrobial and immune modulatory effects of lactic acid and short chain fatty acids produced by vaginal microbiota associated with eubiosis and bacterial vaginosis. Front. Physiol. 2015;164(6):01-10.

5. Pavlova S, Kilic A, Kilic S, Nader-Macias M, Simoes J, Tao L. Genetic diversity of vaginal Lactobacilli from women in different countries based on 16S rRNA gene sequences. J. Appl. Microbiol.2002;92(3):451-9.

6. Damelin L, Paximadis M, Mavri-Damelin D, Birkhead M, Lewis D, Tiemessen C. Identification of predominant culturable vaginal Lactobacillus species and associated bacteriophages from women with and without vaginal discharge syndrome in South Africa. J. Med. Microbiol.2011;60(2):180-3.

7. Dobaria N, Mashru R, Vadia N. Vaginal drug delivery systems: A review of current status. East Cent. Afr. J. Pharm. Sci.. 2007;10:3-13.
8. Bannatyne R, Smith A. Recurrent bacterial vaginosis and metronidazole resistance in Gardnerella vaginalis. Sex. Transm. Infect. 1998;74(6):455-65.

9. Karthick A, Devi D, Vedhahari B. Vaginitis: Recent formulation approaches of anti-infectious drugs. Int. J. Pharm. Bio. Sci. 2014;5(3):212-8.

10. Reid G. Probiotic agents to protect the urogenital tract against infection. Am. J. Clin. Nutr. 2001;73(2):437-43

11. Mcgroarty J. probiotic use of Lactobacilli in the human female urogenital tract. FEMS Immunol. Med. Microbiol. 1993;6(4):251-64.

12. Burton J, Cadieux P, Reid G. Improved understanding of the bacterial vaginal microbiota of women before and after probiotic instillation. Appl. Environ. Microbiol. 2003;69(1):97-101.

13. Gibson G. Dietary modulation of the human gut microflora using prebiotics. Br. J. Nutr. 1998;80(4):09-12.

14. Rousseaua V, Lepargneurb J, Roquesc C, Simeond M, Paula F. Prebiotic effects of oligosaccharides on selected vaginal Lactobacilli and pathogenic microorganisms. Anaerobe. 2005;11(3):145-53.

15. Garg KB, Ganguli I, Das R, Talwa GP. Spectrum of Lactobacillus species present in healthy vagina of Indian women. Indian. J. Med. Res. 2009;129:652-57.

16. Belma A, Kilic E. Some probiotic properties of vaginal Lactobacilli isolated from healthy women. Jpn. J. Infect. 2006;59(4):249-53.

17. Olson D, Aryana K. Effect of prebiotics on Lactobacillus acidophilus growth and resulting $\mathrm{pH}$ changes in skim milk and a model peptone system. J. Microb. Biochem. Technol. 2012;4:121-5

18. Riaz S, Nawaz S, Hasnain S. Bacteriocins produced by L. Fermentum and L. acidophilus can inhibit cephalosporin resistant E. coli. Brazil. J. Microb. 2010;41(3):643-8

19. Farinha L, Sabo S, Porto M, Souza E, Oliveira M, Oliveira R. Influence of Prebiotic Ingredients on the Growth Kinetics and Bacteriocin Production of Lactococcus lactis. Chemical Engineering Transactions. 2015;43:313-8.

20. Coste I, Philippe J, Lepargneur J, Antoun S. Safety and efficacy of an intra-vagina prebiotic gel in the prevention of recurrent bacterial vaginosis: a randomized double-blind study. Obstet. Gynecol. Int. 2012;7:01-07.

21. Borges S, Silva J, Teixeira P. The role of Lactobacilli and probiotics in maintaining vaginal health. Arch. Gynecol. Obstet. 2014;289(3):479-89.

22. Olson D, Aryana K. Effect of prebiotics on Lactobacillus acidophilus growth and resulting $\mathrm{pH}$ changes in skim milk and a model peptone system. J. Microb. Biochem. Technol.2012;4:121-5.

23. Ghazzewi F, Tester R. Biotherapeutic agents and vaginal health: A review J. Appl. Microbiol. 2016;121(1):1364-507213

24. O'bryan C, Pak D, Crandall P, Lee S, Ricke S. The role of prebiotics and probiotics in human health. J. Prob. Health. 2013;1(2):01-08.

25. Moghaddam M, Sattari M, Mobarez A, Doctorzadeh F. Inhibitory effect of yogurt Lactobacilli bacteriocins on growth and verotoxins production of enterohemorrhagic Escherichia coli. Pak. J. Biol. 2006;9(11):2112-6.

26. Borges S, Silva J, Teixeira P. The role of Lactobacilli and probiotics in maintaining vaginal health. Arch. Gynecol. Obstet. 2014;289(3):479-89

Article History: Submission Date : 27-06-2017; Revised Date : 24-07-2017; Acceptance Date : 25-08-2017.

Cite this article: Mahore JG, Rohit BB, Deshkar SS. Investigation of Oligosaccharides for Prebitoic Action on Vaginal Lactobacilli. J Young Pharm. 2017;9(4):502-6. 